\title{
Comorbid Chronic Illness and the Diagnosis and Treatment of Depression in Safety Net Primary Care Settings
}

\author{
Chizobam Ani, MD, MPH, Mobsen Bazargan, PhD, David Hindman, PhD, \\ Douglas Bell, MD, PhD, Michael Rodriguez, MD, MPH, and Richard S. Baker, MD
}

Objective: To estimate the impact of chronic medical conditions on depression diagnosis, treatment, and follow-up care in primary care settings.

Design: This was a cross-sectional study that used interviewer-administered surveys and medical record reviews. Three hundred fifteen participants were recruited from 3 public primary care clinics. Depression diagnosis, guideline-concordant treatment, and follow-up care were the primary outcomes examined in individuals with depression alone compared with individuals with depression and chronic medical conditions measured using the Charlson Comorbidity Index (CCI).

Results: Physician diagnosis of depression (32.6\%), guideline-concordant depression treatment (32.7\%), and guideline-concordant follow-up care (16.3\%) were all low. Logistic regression analysis showed no significant difference in the likelihood of depression diagnosis, guideline-concordant treatment, or follow-up care in individuals with depression alone compared with those with both depression and chronic medical conditions. Participants with severe depression were, however, twice as likely to receive a diagnosis of depression as participants with moderate depression. In addition, participants with moderately severe and severe depression received much less appropriate follow-up care than participants with moderate depression. Among participants receiving a depression diagnosis, $74 \%$ received guideline-concordant treatment.

Conclusion: Physician depression care in primary care settings is not influenced by competing demands for care for other comorbid medical conditions. (J Am Board Fam Med 2009;22:123-135.)

\section{Background}

One hundred and twenty-five million people in the United States suffer from a chronic physical condition, and approximately 60 million of these have

This article was externally peer reviewed.

Submitted 9 February 2008; revised 9 June 2008; accepted 17 June 2008

From the Charles Drew University of Medicine and Science, Los Angeles, CA (CA, MB, DH, RB); and the David Geffen School of Medicine, University of California-Los Angeles (DB, MR).

Funding: Funding was provided by the Health Resources and Services Administration, Health Communities Access Project. Additional support was from the National Institute of Health grant G12 RRO 3026-22 the National Center for Research Resources, NIH/NCRR/RCMI, NCMHD 5S21MD000103-07 and the National Center on Minority health and Health Disparities (P20MD000148).

Conflict of interest: none declared.

Corresponding author: Mohsen Bazargan, PhD, Associate Professor and Director of Research, Department of Family Medicine, Charles Drew University of Medicine and Science, 1731 East 120th Street, Los Angeles, CA 90059 (Email: mobazarg@cdrewu.edu).

See Related Editorial on Page 110. more than one chronic conditions. ${ }^{1}$ Chronic physical conditions also account for considerably disproportionate health care utilization and cost among affected individuals. ${ }^{2,3}$ Depressive disorders are associated with chronic physical conditions $20 \%$ to $50 \%$ of the time, ${ }^{4-10}$ with such co-occurrence reported to predict higher morbidity and worse treatment outcomes. ${ }^{11-28}$

Primary care settings are important for the treatment of many mental health conditions, and primary care providers are often the sole contacts for more than $50 \%$ of patients with a mental illness. ${ }^{29-31}$ These settings are also important health care delivery platforms for individuals with chronic physical conditions, particularly minority Hispanic and African-American populations. However, the quality of depression care in these settings is often poor; depression is under-diagnosed and undertreated close to $50 \%$ to $65 \%$ of the time in these settings. ${ }^{32,33}$ Many factors have been attributed to this poor quality of depression care, including provider-related factors such as disposition, skills, attitudes, and practice toward mental health care as 
well as patient-related factors including perceived stigma associated with mental disorders and treatment, preponderance of somatic symptomatology, and a lack of patient awareness of psychological distress. ${ }^{34-36}$

There is some evidence that multiple competing demands affect the quality of care provided in primary care settings for many medical conditions, ${ }^{37-43}$ with some studies beginning to examine the effects of these demands on mental health care. ${ }^{44-47}$ However, the evidence is mixed regarding the relative effects of comorbid physical conditions on depression care. In 2000, 2 studies reported that chronic physical comorbidity decreased the probability of depression being discussed or noticed during a clinic encounter. ${ }^{46,48}$ Another study in 2002, however, reported similar rates of treatment of patients with depression alone when compared with patients with depression and comorbid physical conditions but worse depression outcomes in the later group. ${ }^{49}$ Similarly, a more recent study also found that depressed people with chronic medical conditions were significantly more likely to receive guideline-level care for depression than were depressed people without chronic medical conditions. ${ }^{50}$ In another study, Harman et al ${ }^{51}$ reported that competing demands did not result in lower quality of depression treatment in older people. There is a strong need for further clarity regarding the role of comorbid chronic conditions on the quality of depression care observed in primary care settings, particularly public safety-net settings serving underserved Hispanic and African-American populations.

\section{Objectives}

This study estimated the association of comorbid chronic medical conditions with the diagnosis, treatment, and follow-up care for depression in Hispanic and African-American individuals receiving health care in safety-net primary care settings. We hypothesize that competing demands will reduce the likelihood of good quality depression care for individuals with both depression and comorbid medical conditions when compared with individuals with depression alone.

\section{Study Setting}

This study was conducted at 3 inner-city outpatient primary care clinics with more than 50 physicians serving primarily underserved Hispanic and African-American patients. This study represents the practice patterns of all providers at the study sites. These sites were also all residency training sites, providing care to more than 30,000 unduplicated individuals annually.

\section{Design}

A cross-sectional design using interviewer-administered surveys and medical record reviews after clinic visits was used. Interviewer-administered depression assessment surveys were conducted with a systematically selected sample of participants. The last patient (most recent arrival) on the waiting list for the clinic was approached for an interview. Participants consenting to an interview were first screened for depression using a 2-item depression screener (Patient Health Questionnaire [PHQ] 2). ${ }^{52}$ Patients screening positive (score of 3 or greater) were then invited to participate in a more in-depth depression assessment using the PHQ-9. ${ }^{53,54}$ The PHQ-9 is a brief, 9-item patient self-report depression assessment tool specifically developed for primary care settings. The PHQ-9 scores each of the 9 symptoms of depression from the Diagnostic and Statistical Manual of Mental Disorders-IV through patients' self-report of each symptom over a 2-week period as "0" (not at all), "1" (several days), "2" (more than half the days), or " 3 " (nearly every day), with possible scores ranging from 0 to 27. The PHQ-9 has demonstrated acceptable reliability, validity, sensitivity, and specificity (PHQ-9 score $>10$ has a sensitivity of $88 \%$ and a specificity of $88 \%$ for major depression). ${ }^{53-56}$ Finally, participants' medical records were reviewed after their clinic visits to document diagnosis, treatment recommendations, recommended follow-up care, and depression diagnosis within 9 months preceding the visit. This study was approved by the institutional review boards of all the sites and interviews were conducted using English and Spanish survey instruments.

\section{Participants}

Participants were eligible to participate in the study if they were positive for depression on assessment with the PHQ-9, had no previous diagnosis of a depressive disorder within 9 months preceding the interview, were 18 years of age or older, spoke English or Spanish, and consented to a review of their medical records (Table 1). 


\section{Outcome Measures}

\section{Physician Diagnosis of Depression}

Depression diagnosis documented in participant's medical records were abstracted and recorded, with $0=$ no depression diagnosis or $1=$ depression diagnosis. All participants had no previously documented diagnosis of depression in their medical record within the 9 months before the study.

\section{Guideline-Concordant Depression Treatment}

Treatment recommendations were adopted from the MacArthur Foundation's initiative on depression and primary care. ${ }^{57}$ This measure was abstracted from participants' medical records and dichotomized with 1 = guideline-concordant care, consistent with (1) antidepressant and or psychotherapy for participants with a PHQ-9 score of 15 or greater and (2) education/supportive counseling for PHQ-9 scores of 10 to 14 at the encounter or diagnostic visit. Care not consistent with these guidelines, including lack of care initiation, was recorded as 0 , non-guideline-concordant care.

\section{Depression Follow-up Care}

The measure was also adopted from the Macarthur foundation's initiative on depression and primary care. ${ }^{57}$ This guideline is a modification of the Agency for Health Research and Quality "guidelines for recommended depression follow-up visits." This measure was abstracted from participant's medical records and dichotomized with 1 = guideline-concordant care/follow-up care, consistent with physician follow-up recommendations within (A) 4 weeks for participants scoring 10 to 14 on the PHQ-9; (B) 2 weeks for participants scoring 15 to 19 on the PHQ-9; or (C) 1 week for participants scoring $\geq 20$ on the PHQ-9. Follow-up recommendations not consistent with these guidelines was recorded as 0, non-guideline-concordant follow-up care.

\section{Independent Measures}

Depression

The presence of depression was determined using a PHQ-9 score of 10 or greater. Participants with scores of less than 10 were classified as mildly depressed or not depressed.

\section{Comorbid Chronic Physical Condition}

Comorbidities abstracted from patients' medical records were quantified using methods described
Table 1. Characteristics of the Study Sample $(n=315)$

\begin{tabular}{|c|c|}
\hline Variables & $\begin{array}{l}\text { Frequency } \\
(\mathrm{n}[\%])\end{array}$ \\
\hline \multicolumn{2}{|l|}{ Gender } \\
\hline Male & $72(22.9)$ \\
\hline Female & $243(77.1)$ \\
\hline \multicolumn{2}{|l|}{ Age (years) } \\
\hline $18-44$ & $94(29.8)$ \\
\hline $45-54$ & $104(33.0)$ \\
\hline$\geq 55$ & $117(37.1)$ \\
\hline Mean age (SD) & $49.85(10.80)$ \\
\hline \multicolumn{2}{|l|}{ Ethnicity } \\
\hline Latino/Hispanic & $192(61.0)$ \\
\hline Black/African-American & $71(22.5)$ \\
\hline Other* & $52(16.5)$ \\
\hline \multicolumn{2}{|l|}{ Health insurance status } \\
\hline No health insurance coverage & $160(50.7)$ \\
\hline Some source of health insurance & $155(49.3)$ \\
\hline \multicolumn{2}{|l|}{ Medical visits during past 12 months (n) } \\
\hline 1 & $177(56.2)$ \\
\hline $2-3$ & $58(18.4)$ \\
\hline$\geq 4$ & $80(25.4)$ \\
\hline \multicolumn{2}{|l|}{$\begin{array}{l}\text { Depression and chronic physical } \\
\text { conditions }\end{array}$} \\
\hline $\begin{array}{l}\text { Depression no chronic physical } \\
\text { condition }(\text { CCI score }=0 \text { ) }\end{array}$ & $86(27.3)$ \\
\hline $\begin{array}{l}\text { Depression and chronic physical } \\
\text { condition (moderate CCI score } \\
=1-2 \text { ) }\end{array}$ & $106(33.7)$ \\
\hline $\begin{array}{l}\text { Depression and chronic physical } \\
\text { Condition (severe CCI score } \geq 3 \text { ) }\end{array}$ & $123(39.0)$ \\
\hline \multicolumn{2}{|l|}{ Depression severity } \\
\hline Moderate & $103(32.7)$ \\
\hline Moderately severe & $131(41.6)$ \\
\hline Severe & $81(25.7)$ \\
\hline \multicolumn{2}{|l|}{ Physician depression diagnosis } \\
\hline Not diagnosed & $207(67.4)$ \\
\hline Diagnosed & $100(32.6)$ \\
\hline \multicolumn{2}{|l|}{ Depression treatment ${ }^{\ddagger}$} \\
\hline Non-guideline-concordant & $212(67.3)$ \\
\hline Guideline-Concordant & $103(32.7)^{\dagger}$ \\
\hline \multicolumn{2}{|l|}{ Depression follow-up care ${ }^{\ddagger}$} \\
\hline Non-guideline-concordant & $236(83.7)$ \\
\hline Guideline concordant & $46(16.3)$ \\
\hline
\end{tabular}

* "Others" here refer to whites, Asian-Americans, and all other ethnicities.

${ }^{\dagger}$ Included 3 patients without a documented diagnosis of depression.

${ }^{\ddagger}$ Among all participants regardless of diagnosis status. CCI, Charlson Comorbidity Index.

by Charlson et al. ${ }^{58}$ The CCI includes 19 diseases weighted based on their association with mortality. ${ }^{58}$ The CCI is not an exhaustive list of all possible comorbid conditions, but is rather a weighted index of 
19 selected categories of disease that were found to be associated with mortality and other important health outcomes. Increasing scores on the CCI reflect an increasing burden of comorbid conditions. ${ }^{58,59} \mathrm{~A}$ variable was then created with 3 categories: (1) participants with no comorbidity and depression alone $=$ 0 ; (2) participants with a comorbidity index of 1 to 2 and depression $=1$; and (3) participants with a comorbidity index of 3 or greater and depression $=2$.

\section{Health Care Utilization}

Total number of medical visits in the past 12 months was abstracted from participant medical records for the 12 months preceding the interview and were recorded in 3 categories: (1) one visit; (2) 2 to 3 visits; or (3) 4 or more visits.

\section{Depression Severity}

This measure was adapted from the 2001 Kroenke et al study. ${ }^{54}$ PHQ-9 scores of $<10,10$ to 14,15 to 19 , and $\geq 20$ representing "no or mild depression" (0), moderate depression (1), moderately severe depression (2), and severe depression (3), respectively. A score of 10 or greater was selected because it demonstrates a sensitivity of $88 \%$ and a specificity of $88 \%$ for major depression.

\section{Other Measures}

Demographic characteristics of study participants, including age, ethnicity, gender, and health insurance status, were also recorded.

\section{Statistical Analysis}

The impact of chronic physical conditions on the diagnosis, treatment, and follow-up care of depression was explored in several ways. First, the frequency and distribution of all of the outcome and independent variables was determined. Next, bivariate analysis using $\chi^{2}$ tests was performed to document the independent relationship between these variables in individuals with depression alone compared with individuals with depression and chronic medical conditions. Another series of bivariate analysis was also conducted to examine the same relationships in individuals with depression alone compared with individuals with depression and either of the 2 categories of chronic medical conditions computed using the CCI (moderate score of 1 to 2 and severe score of $\geq 3$ ). We then constructed 3 separate binary logistic regression models to determine the likelihood that individuals with depres- sion alone compared with individuals with depression and chronic physical cognitions will be diagnosed by physicians and receive guideline-concordant care and guideline-concordant follow-up care while controlling for variables demonstrated to be associated with depression quality of care. $^{46,48-50,60-63}$

Unadjusted logistic regression analysis was first conducted with all of the variables chosen for the final models. Although this study's primary intent was to evaluate the relationship between chronic physical conditions and depression, the dependent variable in the regression models was the likelihood of achieving any of the defined outcomes (depression diagnosis, guideline-concordant treatment, or guideline-concordant follow-up care), we included demographic characteristics and frequency of medical visits in the past 12 months because bivariate analysis showed that these variables demonstrated statistically significant differences when we compared depressed individuals with individuals with depression and chronic physical conditions. Finally, we constructed a final regression model to determine the likelihood that participants with a physician diagnosis of depression will receive guidelineconcordant care or follow-up care while controlling for selected demographic characteristics and depression severity. Correlations between independent variables were examined to check for multicolinearity.

\section{Results}

A total of 2540 participants were screened for depression using the PHQ-2. ${ }^{52}$ Of these, 415 participants scoring $\geq 3$ on the PHQ-2 screener were further screened using the PHQ-9. A total of 315 participants scored $\geq 10$ and met the PHQ-9 criteria for moderate-severe depression. Specifically, $229(72.3 \%)$ and 123 (39.0\%), respectively, had a chronic medical condition defined by a CCI score of $\geq 1 ; 243$ (77.1\%) were women; 221 (70.1\%) were aged 45 years or older; 207 (66.7\%) did not receive a diagnosis of depression; $212(67.3 \%)$ did not receive guideline-concordant care; and 236 $(83.7 \%)$ did not get guideline-concordant follow-up care for depression. Table 2 presents more details of the characteristics of the study sample.

Bivariate analysis comparing individuals with depression and individuals with depression and chronic medical conditions showed that being of 
Table 2. Bivariate Analysis Outcome and Independent Variable in Patients with Depression with No Chronic Physical Condition Vs Patients with Moderate Charlson Comorbidity Index (CCI) Score of 1 to 2 and Depression Vs Patients with a Severe Charlson Comorbidity Index Score of $\geq 3$ and Depression

\begin{tabular}{|c|c|c|c|c|}
\hline Variables & $\begin{array}{c}\text { Depression with No } \\
\text { Chronic Condition } \\
\text { (n }[\%])\end{array}$ & $\begin{array}{l}\text { Depression with Chronic } \\
\text { Condition }(\mathrm{s})^{*}(\mathrm{n}[\%])\end{array}$ & $\begin{array}{l}\text { Depression with Chronic } \\
\text { Condition }(\mathrm{s})^{\dagger}(\mathrm{n}[\%])\end{array}$ & $\chi^{2}(P)$ \\
\hline $\begin{array}{c}\text { Physician depression } \\
\text { diagnosis }\end{array}$ & & & & $0.130(.937)$ \\
\hline Not diagnosed & $60(27.9)$ & $72(33.5)$ & $83(38.6)$ & \\
\hline Diagnosed & $26(26.0)$ & $34(34.0)$ & $40(40.0)$ & \\
\hline Depression treatment & & & & $2.194(.334)$ \\
\hline $\begin{array}{l}\text { Non-guideline } \\
\text { concordant }\end{array}$ & $25(25.0)$ & $30(30.0)$ & $45(45.0)$ & \\
\hline Guideline concordant & $61(28.4)$ & $76(35.3)$ & $78(36.3)$ & \\
\hline $\begin{array}{l}\text { Depression follow-up } \\
\text { care }\end{array}$ & & & & $3.577(.167)$ \\
\hline $\begin{array}{l}\text { Non-guideline } \\
\text { concordant }\end{array}$ & $54(22.9)$ & $88(37.3)$ & $94(39.8)$ & \\
\hline Guideline concordant & $15(32.6)$ & $11(23.9)$ & $20(43.5)$ & \\
\hline Depression everity & & & & $2.562(.634)$ \\
\hline Moderate & $33(32.0)$ & $34(33.0)$ & $36(35.0)$ & \\
\hline Moderately severe & $31(23.7)$ & $47(35.9)$ & $53(40.5)$ & \\
\hline Severe & $22(27.2)$ & $25(30.9)$ & $34(42.0)$ & \\
\hline $\begin{array}{l}\text { Medical visits during past } \\
12 \text { months (n) }\end{array}$ & & & & $7.239(.124)$ \\
\hline 1 & $58(32.8)$ & $58(32.8)$ & $61(34.5)$ & \\
\hline $2-3$ & $13(12.4)$ & $21(36.2)$ & $24(41.4)$ & \\
\hline$\geq 4$ & $15(18.8)$ & $27(33.8)$ & $38(47.5)$ & \\
\hline Age (years) & & & & $102.852^{\ddagger}(<.001)$ \\
\hline $18-44$ & $44(46.8)$ & $41(43.6)$ & $9(9.6)$ & \\
\hline $45-54$ & $25(24.0)$ & $50(48.1)$ & $29(27.9)$ & \\
\hline$\geq 55$ & $17(14.5)$ & $15(12.8)$ & $85(72.6)$ & \\
\hline Ethnicity & & & & $14.368^{\S}(.006)$ \\
\hline Latino/Hispanic & $45(23.4)$ & $66(34.4)$ & $81(42.2)$ & \\
\hline $\begin{array}{l}\text { Black/African- } \\
\text { American }\end{array}$ & $16(22.5)$ & $25(35.2)$ & $50(42.3)$ & \\
\hline Other & $25(48.1)$ & $15(28.8)$ & $12(23.1)$ & \\
\hline Gender & & & & $0.646(.724)$ \\
\hline Male & $19(26.4)$ & $27(37.5)$ & $26(36.1)$ & \\
\hline Female & $67(27.6)$ & $79(32.5)$ & $97(39.9)$ & \\
\hline
\end{tabular}

${ }^{*}$ Moderate CCI score $=1-2$.

${ }^{+}$Severe CCI score $=\geq 3$.

${ }^{\ddagger} P<.050$ is significant.

${ }^{\S} \mathrm{P}<.001$ is significant.

Latino and African-American ethnicity, older, and having more frequent hospital visits within the past 12 months was significantly associated with the co-occurrence of depression and chronic medical conditions (Table 3). Being of Latino and AfricanAmerican ethnicity and older age was also statistically significantly associated with the co-occurrence of depression and chronic medical conditions using 2 separate chronic comorbidity categories
(CCI score of 1 to 2 or $\geq 3$ ). Tables 2 and 3 present a more detailed description of the bivariate analysis results.

\section{Physician Diagnosis of Depression}

There was no statistically significant difference in the likelihood that individuals with depression alone would be diagnosed by physicians with depression when compared with individuals with de- 
Table 3. Bivariate Analysis Outcome and Independent Variable in Patents with Depression with No Chronic Physical Condition vs Paitents with Chronic Physical Conditions (Charlson Comorbidity Index score $\geq 1$ ) with Depression

\begin{tabular}{|c|c|c|c|}
\hline Variables & $\begin{array}{l}\text { Depression with No Chronic } \\
\text { Condition (n [\%]) }\end{array}$ & $\begin{array}{l}\text { Depression with Chronic } \\
\text { Condition }(\mathrm{s})^{*}(\mathrm{n}[\%])\end{array}$ & $\chi^{2}(P)$ \\
\hline Physician dpression dagnosis & & & $0.125(.724)$ \\
\hline Not dagnosed & $60(69.8)$ & $155(67.7)$ & \\
\hline Diagnosed & $26(30.2)$ & $74(32.3)$ & \\
\hline Deression treatment & & & $0.391(.532)$ \\
\hline Non-guideline concordant & $61(70.9)$ & $154(67.2)$ & \\
\hline Guideline concordant & $25(29.1)$ & $75(32.8)$ & \\
\hline Depression follow-up care & & & $1.971(.160)$ \\
\hline Non-guideline concordant & $54(78.3)$ & $182(85.4)$ & \\
\hline Guideline concordant & $15(21.7)$ & $31(14.6)$ & \\
\hline Depression severity & & & $2.039(.361)$ \\
\hline Moderate & $33(38.4)$ & $70(30.6)$ & \\
\hline Moderately severe & $31(36.0)$ & $100(43.7)$ & \\
\hline Severe & $22(25.6)$ & $59(25.8)$ & \\
\hline Medical visits during past 12 months (n) & & & $6.311(.043)^{\dagger}$ \\
\hline 1 & $58(67.4)$ & $119(52.0)$ & \\
\hline $2-3$ & $13(15.1)$ & $45(19.7)$ & \\
\hline$\geq 4$ & $15(17.4)$ & $65(28.4)$ & \\
\hline Age (years) & & & $28.195(<.001)^{\ddagger}$ \\
\hline $18-44$ & $44(51.2)$ & $50(21.8)$ & \\
\hline $45-54$ & $25(29.1)$ & $79(34.5)$ & \\
\hline$\geq 55$ & $17(19.8)$ & $100(43.7)$ & \\
\hline Ethnicity & & & $13.56(.001)^{\dagger}$ \\
\hline Latino/Hispanic & $45(53.3)$ & $147(64.2)$ & \\
\hline Black/African-American & $16(18.6)$ & $55(24.0)$ & \\
\hline Other & $25(29.1)$ & $27(11.8)$ & \\
\hline Gender & & & $0.039(.843)$ \\
\hline Male & $19(22.1)$ & $53(23.1)$ & \\
\hline Female & $67(77.9)$ & $176(22.9)$ & \\
\hline
\end{tabular}

${ }^{*}$ Charlson Comorbidity Index score $\geq 1$.

${ }^{\dagger} P<.050$ is significant.

${ }^{\ddagger} P<.001$ is significant.

pression and the 2 categories of chronic medical conditions computed using the CCI (moderate score of 1 to 2 and severe score of $\geq 3$ ) using logistic regression analysis (odds ratio, 1.09; 95\% CI, 0.592.02 and odds ratio, 1.11 ; 95\% CI, 0.61-2.02, respectively). Even when we adjusted for demographic characteristics, frequency of medical visits in the past 12 months, and depression severity there was still no statistically significant difference in the likelihood of a physician depression diagnosis being made (odds ratio, 1.26; 95\% CI, $0.66-2.45$ and odds ratio, 1.56 ; 95\% CI, 0.74-3.31, respectively) (Table 4). Participants with severe depression were, however, statistically significantly more likely to be diagnosed with depression by physicians when compared with participants with moderate depression in both the bivariate and adjusted logistic regression models (odds ratio, 2.25, 95\% CI, $0.21-$ 4.21 and odds ratio, $2.10,95 \%$ CI, 1.11-3.98, respectively)

\section{Guideline-Concordant Depression Care}

Among individuals diagnosed with depression by physicians there was no statistically significant difference in the likelihood of receiving guidelineconcordant depression care when individuals with depression alone were compared with both individuals with depression or a moderate CCI score of 1 to 2 or severe CCI score of $\geq 3$. Table 5 presents a 
Table 4. Binary Logistic Regression: Physician Depression Diagnosis vs Independent Variables

\begin{tabular}{|c|c|c|c|c|}
\hline Variables & $P^{*}$ & Unadjusted OR (95\% CI) & $P^{\dagger}$ & Adjusted OR (95\% CI) \\
\hline \multicolumn{5}{|l|}{ Chronic medical condition } \\
\hline $\begin{array}{l}\text { No chronic medical condition; depression } \\
\text { only (Ref) }\end{array}$ & N/A & $1.00(-)$ & N/A & $1.00(-)$ \\
\hline Depression with moderate CCI score of $1-2$ & .784 & $1.09(0.59-2.02)$ & .48 & $1.26(0.66-2.45)$ \\
\hline Depression with severe CCI score of $\geq 3$ & .726 & $1.11(0.61-2.02)$ & .24 & $1.56(0.74-3.31)$ \\
\hline \multicolumn{5}{|l|}{ Depression severity } \\
\hline Moderate (Ref) & N/A & $1.00(-)$ & N/A & $1.00(-)$ \\
\hline Moderately severe & .44 & $1.26(0.70-2.25)$ & .492 & $1.23(0.68-2.22)$ \\
\hline Severe & .01 & $2.25^{*}(1.21-4.21)$ & .02 & $2.10^{*}(1.11-3.98)$ \\
\hline \multicolumn{5}{|l|}{ Medical visits during past 12 months (n) } \\
\hline 1 (Ref) & N/A & $1.00(-)$ & N/A & $1.00(-)$ \\
\hline $2-3$ & .99 & $1.01(0.53-1.88)$ & .90 & $0.98(0.51-1.89)$ \\
\hline$\geq 4$ & .52 & $0.83(0.47-1.47)$ & .47 & $0.82(0.42-1.48)$ \\
\hline \multicolumn{5}{|l|}{ Age (years) } \\
\hline 18-44 (Ref) & N/A & $1.00(-)$ & N/A & $1.00(-)$ \\
\hline $45-54$ & .52 & $1.21(0.68-2.16)$ & .44 & $0.78(0.41-1.47)$ \\
\hline$\geq 55$ & .77 & $1.09(0.62-1.93)$ & .23 & $0.63(0.3-1.34)$ \\
\hline \multicolumn{5}{|l|}{ Gender } \\
\hline Male (Ref) & N/A & $1.00(-)$ & N/A & $1.00(-)$ \\
\hline Female & .16 & $1.53(0.84-2.77)$ & .22 & $1.465(0.793-2.706)$ \\
\hline \multicolumn{5}{|l|}{ Ethnicity } \\
\hline Latino/Hispanic (Ref) & N/A & $1.00(-)$ & N/A & $1.000(-)$ \\
\hline African-American & .22 & $0.67(0.36-1.26)$ & .47 & $0.79(0.42-1.49)$ \\
\hline Non-African-American and Others) & .11 & $0.54(0.25-1.16)$ & .16 & $1.65(0.83-3.29)$ \\
\hline \multicolumn{5}{|l|}{-2 likelihood of final model $=380.6$} \\
\hline Nagelkerke $R_{2}=0.057$ & & & & \\
\hline
\end{tabular}

${ }^{*} P<.050$ is significant.

${ }^{\dagger} P<.001$ is significant.

OR, odds ratio; CCI, Charlson Comorbidity Index; Ref, reference category.

more detailed description of the logistic regression analysis results.

\section{Guideline-Concordant Depression Follow-up Care}

For guideline-concordant follow-up care, the conducted multivariate analysis estimated the likelihood of receiving appropriate follow-up care when controlling for demographic characteristics and depression severity of the sample. We removed variable of the frequency of clinic visits during the previous 12 months in the model because it is a component of the follow-up care outcome variable. We also used a dichotomized depression and chronic medical condition variable (moderate CCI score of 1 to 2 and severe CCI score of $\geq 3$ ) instead of all 3 categories because of the small sample size and potential instability of the regression model.

Considering individuals diagnosed with depression by physicians, there was a reduced likelihood of receiving guideline-concordant depression care when patients with depression alone where compared with patients with a chronic medical condition, even though there was no statistically significant difference in both the unadjusted and adjusted logistic regression analysis (unadjusted odds ratio, $0.41 ; 95 \%$ CI, $0.12-1.14$ and adjusted odds ratio, 0.29; 95\% CI, 0.06-1.49). However, study participants with moderately severe (unadjusted odds ratio, $0.14 ; 95 \%$ CI, $0.03-0.60$ and the adjusted odds ratio, $0.11 ; 95 \% \mathrm{CI}, 0.02-0.55)$ and severe depression (unadjusted odds ratio, 0.50; 95\% CI, 0.010.42 and the adjusted odds ratio, $0.04 ; 95 \%$ CI, 0.01-0.41), respectively, were much less likely to receive guideline-concordant follow-up care when compared with participants with moderate depression on unadjusted and bivariate regression analysis. Neither age, gender, nor ethnicity were significant predictors of appropriate follow-up care in 
Table 5. Binary Logistic Regression: Guideline-Concordant Depression Care Vs Independent Variables*

\begin{tabular}{|c|c|c|c|c|}
\hline Variables & $P^{\dagger}$ & Unadjusted OR (95\% CI) & $P^{\ddagger}$ & Adjusted OR (95\% CI) \\
\hline \multicolumn{5}{|l|}{ Chronic medical condition } \\
\hline $\begin{array}{l}\text { No chronic medical condition; depression only } \\
\text { (Ref) }\end{array}$ & N/A & $1.00(-)$ & N/A & $1.000(-)$ \\
\hline Depression with moderate CCI score of $1-2$ & .26 & $0.50(0.15-1.67)$ & .56 & $0.65(0.16-2.73)$ \\
\hline Depression with severe CCI score of $\geq 3$ & .59 & $0.71(0.21-2.40)$ & .41 & $0.54(0.13-2.32)$ \\
\hline \multicolumn{5}{|l|}{ Depression Severity } \\
\hline Moderate (Ref) & N/A & $1.00(-)$ & N/A & $1.00(-)$ \\
\hline Moderately severe & .17 & $0.41(0.12-1.45)$ & .13 & $0.34(0.08-1.36)$ \\
\hline Severe & .23 & $0.46(0.13-1.66)$ & .18 & $0.38(0.09-1.57)$ \\
\hline \multicolumn{5}{|l|}{ Total Number of Medical visits in past 12 months } \\
\hline 1 (Ref) & N/A & $1.00(-)$ & N/A & $1.00(-)$ \\
\hline $2-3$ & .26 & $0.50(0.15-1.67)$ & .33 & $1.99(0.50-7.85)$ \\
\hline$\geq 4$ & .59 & $0.71(0.21-2.40)$ & .96 & $0.97(0.298-3.18)$ \\
\hline \multicolumn{5}{|l|}{ Age (years) } \\
\hline $18-44$ (Ref) & N/A & $1.00(-)$ & N/A & $1.00(-)$ \\
\hline $45-54$ & .93 & $1.05(0.37-3.00)$ & .90 & $0.93(0.29-2.95)$ \\
\hline$\geq 55$ & .18 & $2.20(0.69-6.97)$ & .26 & $2.36(0.53-10.58)$ \\
\hline \multicolumn{5}{|l|}{ Gender } \\
\hline Male (Ref) & N/A & $1.00(-)$ & N/A & $1.00(-)$ \\
\hline Female & .17 & $2.11(0.72-6.20)$ & .10 & $2.82(0.82-9.75)$ \\
\hline \multicolumn{5}{|l|}{ Ethnicity } \\
\hline Latino/Hispanic (Ref) & N/A & $1.00(-)$ & N/A & $1.00(-)$ \\
\hline African-American & .79 & $0.87(0.28-2.62)$ & .78 & $0.83(0.23-3.04)$ \\
\hline Non-African-American and Others & .21 & $2.37(0.62-9.11)$ & .42 & $1.82(0.43-7.83)$ \\
\hline \multicolumn{5}{|l|}{$-2 \log$ likelihood of final model $=0.146$} \\
\hline Nagelkerke $R_{2}=104.1$ & & & & \\
\hline
\end{tabular}

${ }^{*}$ Participants with a physician diagnosis of depression $=100$.

${ }^{\dagger} P<.050$ is significant.

${ }^{\ddagger} P<.001$ is significant.

OR, odds ratio; Ref, reference category; CCI, Charlson Comorbidity Index.

patients diagnosed by physicians with depression (Table 6).

\section{Discussion}

When setting out to examine the influence of comorbid medial conditions, we hypothesized that competing demands would reduce the likelihood of good quality depression care of patients with both depression and comorbid medical conditions as compared with patients with depression alone. We also sought to clarify the relationship between these demands and good quality care, particularly because the evidence regarding the potential effects of comorbidity on depression care is mixed. ${ }^{46,48-51}$ This study builds on these previous studies. For example, data from a 2000 study by Borowsky et $\mathrm{al}^{48}$ collected some time ago, might not appropriately reflect physician depression care practice, par- ticularly with very concerted efforts made to improve the quality of mental health care in primary care settings. In addition, this same study determined the provider practice of using provider selfreporting of mental health care indices. Similarly, Kurdyak et $\mathrm{al}^{50}$ in 2004 and Rost et $\mathrm{al}^{46}$ in 2000 also used patient self-reports of physician care as a proxy measure of guideline-appropriate care, thus increasing the likelihood of errors associated with under- or over-reporting of physician recommendations. However, our study evaluated actual care practices using medical record reviews as a more objective measure of actual depression care. The key findings from study suggest that (1) the comorbid chronic medical conditions are not associated with a difference in the likelihood of diagnosis, guideline-appropriate treatment, or follow-up care for depression; (2) although severe depression is the 
Table 6. Binary Logistic Regression: Guideline-Concordant Depression Follow-up Care vs Independent Variables*

\begin{tabular}{|c|c|c|c|c|}
\hline Variables & $P^{\dagger}$ & Unadjusted OR (95\% CI) & $P^{\ddagger}$ & Adjusted OR (95\% CI) \\
\hline \multicolumn{5}{|l|}{ Chronic medical condition } \\
\hline $\begin{array}{l}\text { No chronic medical condition; depression } \\
\text { only (Ref) }\end{array}$ & N/A & $1.00(-)$ & N/A & $1.00(-)$ \\
\hline $\begin{array}{l}\text { Depression with chronic conditions (CCI } \\
\text { score } \geq 1 \text { ) }\end{array}$ & .16 & $0.41(0.12-1.14)$ & .15 & $0.29(0.06-1.49)$ \\
\hline \multicolumn{5}{|l|}{ Depression severity } \\
\hline Moderate (Ref) & N/A & $1.00(-)$ & N/A & $1.00(-)$ \\
\hline Moderately severe & .01 & $0.14^{*}(0.03-0.60)$ & .01 & $0.11^{*}(0.02-0.55)$ \\
\hline Severe & .01 & $0.50^{*}(0.01-0.42)$ & .01 & $0.04^{*}(0.01-0.41)$ \\
\hline \multicolumn{5}{|l|}{ Age (years) } \\
\hline 18-44 (Ref) & N/A & $1.00(-)$ & N/A & $1.00(-)$ \\
\hline $45-54$ & .34 & $0.43(0.08-2.43)$ & .46 & $0.44(0.05-3.90)$ \\
\hline$\geq 55$ & .78 & $1.20(0.33-4.41)$ & .48 & $1.90(0.31-10.93)$ \\
\hline \multicolumn{5}{|l|}{ Gender } \\
\hline Male (Ref) & N/A & $1.00(-)$ & N/A & $1.00(-)$ \\
\hline Female & .23 & $0.44(0.12-1.66)$ & .56 & $0.60(0.11-3.31)$ \\
\hline \multicolumn{5}{|l|}{ Ethnicity } \\
\hline Latino/Hispanic (Ref) & N/A & $1.00(-)$ & N/A & $1.00(-)$ \\
\hline African-American & .11 & $2.92(0.79-10.81)$ & .35 & $2.22(0.42-11.77)$ \\
\hline Non-African-American and Others & .39 & $0.39(0.05-3.39)$ & .15 & $0.16(0.01-1.90)$ \\
\hline \multicolumn{5}{|l|}{$-2 \log$ likelihood of final model $=51.0$} \\
\hline Nagelkerke $R_{2}=0.411$ & & & & \\
\hline
\end{tabular}

*Participants with a physician diagnosis of depression $=100$.

${ }^{\dagger} P<.050$ is significant.

${ }^{\ddagger} P<.001$ is significant.

OR, odds ratio; CCI, Charlson Comorbidity Index; Ref, reference category.

only independent predictor of physician depression diagnosis, patients with more severe forms of depression are less likely to receive guideline-appropriate follow-up care when their medical comorbidity status is additionally considered; and (3) the quality of depression care, evidenced by overall low diagnosis and treatment rates, remains poor for patients receiving care in primary care settings. The results of this study regarding the rate of the under-diagnosis of depression is slightly higher than reported in previous studies $(67 \%$ vs $50 \%$ to $65 \%) .{ }^{32,33,64,65}$ These findings suggest an important need to continue exploration of avenues for improving provider recognition of depression in primary care settings.

In contrast to the studies reporting a reduced likelihood of diagnosis of depression when associated comorbid medical conditions occur and consistent with our primary hypothesis, ${ }^{46,48}$ this study found that comorbid medical conditions were not associated with a change in the likelihood of a depression diagnosis by physicians. In fact, the only significant independent predictor of a depression diagnosis was the presence of severe depression, a finding contrary to those reported by Rost et al. ${ }^{46}$

Guidelines provide guidance for depression treatment, including pharmacotherapy, psychotherapy, and adequate follow-up care for reassessment and treatment maintenance or termination in primary care settings. ${ }^{66,67}$ Numerous studies document low rates of adherence to guideline recommendations for antidepressant use or psychotherapy in these same settings. ${ }^{68,69}$ When evaluating the potential impact of comorbid medical conditions on guideline-concordant treatment and follow-up care, the findings of this study suggest low adherence to guideline-recommended care.

Pharmacotherapy has been shown to be effective alone or in combination with psychotherapy in the treatment of depression. ${ }^{70,71}$ It was not surprising that guideline-based treatment was provided to only approximately a third of study participants meeting the PHQ-9 diagnostic criteria for depression because most of the depressed individuals remained undiagnosed. However, it is encouraging to note that, among patients receiving a depression 
diagnosis, approximately $74 \%$ actually received guideline-based treatment. This is similar to findings from a recent (2007) study by Hepner et $\mathrm{al}^{72}$ in which initiation of treatment for depression was also found to be high. The findings in this study of high appropriate treatment rates unassociated with the occurrence of medical comorbidity is consistent with findings that most primary care clinicians are disposed to treat depression and have sufficient competence about appropriate treatment for their patients with depression. ${ }^{73}$

It is also important to note that most of the participants received pharmacotherapy alone (84\%), even though guidelines allow for the recommendation of either pharmacotherapy or psychotherapy, and only $2 \%$ of patients received psychotherapy alone. These results vary from previously reported studies in which only $49 \%$ of the patients with newly diagnosed depression were reported to receive antidepressant medication and between $28 \%$ and $34 \%$ received both psychotherapy and medications. ${ }^{74,75}$ This finding outlines further the importance of physician diagnosis of depression because it suggests that they will appropriately treat once depression is diagnosed. Further studies to explore the relationship between provider preference for pharmacotherapy and established treatment guidelines are required.

It is important to mention a priori that the follow-up care measure used for this study is not an empiric measure of depression-specific follow-up visits. Physician follow-up recommendations were compared with the minimum recommended interval for follow-up visits based on depression severity. ${ }^{57}$ However, guideline-concordant follow-up care is consistently poor even among patients receiving a physician diagnosis of depression (28.3\%); this demonstrates that, unlike the observations regarding treatment for participants diagnosed with depression by physicians, adequate follow-up care for these same patients remains suboptimal. The results are particularly concerning because patients with moderately severe or severe depression are less likely to receive guideline-concordant follow-up care when compared with patients with moderate depression. Surprisingly, the patients who are at the most risk for medication side effects, increased suicidal tendencies, and possible experience of adherence issues are inappropriately followed-up. ${ }^{76}$ In addition, these findings also suggests that an increased exposure to primary care providers re- sulting from the co-occurrence of chronic medical conditions requiring regular follow-up does not improve the likelihood that they will receive appropriate depression care. Finally, this study demonstrates that the co-occurrence of chronic medical conditions with depression is not associated with the diagnosis, treatment, or follow-up care of depression. Even when we controlled for the clinical status of the using a standardized comorbidity index, there were no documented differences in any of these processes of care. All of the multivariate models that controlled for the severity of depression and demographic variables still failed to result in a statistically significant increased likelihood of a difference in these care processes. Summarily, this study's finding that competing demands for care may not plausibly explain the current quality of depression care, particularly among minority underserved populations with limited access to mental health care resources, is important within the following context: the inadequacy of appropriate depression diagnosis during patient visits regardless of comorbidity status underlies the fact that the under-diagnosis and under-treatment of depression may be under the influence of factors other than time-sensitive patient visits and the competition for physician's time. This is particularly important because of evidence suggesting that perceptions of competing demands may affect primary care physician's mental health care practices. ${ }^{77}$ Interventions that promote depression care in primary care settings may find these findings useful for addressing such perceptions. Secondly, as the burden of comorbid chronic medical conditions continue to increase in the United States, these findings continue to suggest an important role for studies and interventions to address the important role of depression on treatment outcomes for comorbid chronic medical conditions, particularly among minority underserved populations.

Our findings are subject to some important limitations. It is important to report that the PHQ-9 is used as the "gold standard" measure for depression. Although PHQ-9 scores of $\geq 10$ have been reported to have a sensitivity of $88 \%$ and a specificity of $88 \%$, some misclassification of depressed individuals may affect the reported study findings. We were unable to further delineate medication dosage for the guideline-concordant depression treatment variable. This information might further stratify identified guideline-concordant care and 
result in an observation of lower frequencies for the guideline-concordant care described by this study. The reliability of medical record abstractions may have also limited our findings; to address this we conducted re-abstractions on no fewer than $10 \%$ of all medical records. We recognize that medical records may not accurately reflect physician practice, but it is noteworthy to mention, however, that, because initiation and continuity of care for depression is based mainly elicitation and recording of verbal assessments rather than empirical biochemical markers, deficiencies in care or documentation represents deficiencies in appropriate care. Finally, it is possible, though unlikely, that the observations of this study may be explained by clustered physician practices.

\section{References}

1. Knickman J, Anderson GF. Chronic care. In: Kovener AR, Knickman JR (eds.). Jonas and Kovner's health care delivery in the United States, 8th ed. New York: Springer Publishing Co; 2005.

2. Patrick DL, Kinne S, Engelberg RA, Pearlman RA. Functional status and perceived quality of life in adults with and without chronic conditions. J Clin Epidemiol 2000;53:779-85.

3. Gijsen R, Hoeymans N, Schellevis FG, Ruwaard D, Satariano WA, van den Bos GA. Causes and consequences of comorbidity: a review. J Clin Epidemiol 2001;54:661-74.

4. Yohannes AM, Baldwin RC, Connolly MJ. Prevalence of sub-threshold depression in elderly patients with chronic obstructive pulmonary disease. Int $\mathrm{J}$ Geriatr Psychiatry 2003;18:412-6.

5. Thombs BD, Hudson M, Taillefer SS, Baron M. Canadian Scleroderma Research Group. Prevalence and clinical correlates of symptoms of depression in patients with systemic sclerosis. Arthritis Rheum 2008;59:504-9.

6. Pieper L, Schulz H, Klotsche J, Eichler T, Wittchen HU. [Depression as a comorbid disorder in primary care.] Bundesgesundheitsblatt Gesundheitsforschung Gesundheitsschutz 2008;51:411-21.

7. Goldston K, Baillie AJ. Depression and coronary heart disease: a review of the epidemiological evidence, explanatory mechanisms and management approaches. Clin Psychol Rev 2008;28:288-306.

8. Friedman B, Lyness JM, Delavan RL, Chunyu L, Barker WH. Major depression and disability in older primary care patients with heart failure. J GeriatrPsychiatry Neurol 2008;21:111-22.

9. Scott KM, Von Korff M, Ormel J, et al. Mental disorders among adults with asthma: results from the World Mental Health Survey. Gen Hosp Psychiatry 2007;29:123-33.
10. Nilsson FM, Kessing LV, Sorensen TM, Andersen PK, Bolwig TG. Major depressive disorder in Parkinson's disease: a register-based study. Acta Psychiatr Scand 2002;106:202-11.

11. Rutledge T, Reis VA, Linke SE, Greenberg BH, Mills PJ. Depression in heart failure a meta-analytic review of prevalence, intervention effects, and associations with clinical outcomes. J Am Coll Cardiol 2006;48:1527-37.

12. Pizzi C, Manzoli L, Mancini S, Costa GM. Analysis of potential predictors of depression among coronary heart disease risk factors including heart rate variability, markers of inflammation, and endothelial function. Eur Heart J 2008;29:1110-7.

13. Mezuk B, Eaton WW, Golden SH. Depression and osteoporosis: epidemiology and potential mediating pathways. Osteoporos Int 2008;19:1-12.

14. Fan AZ, Strine TW, Jiles R, Mokdad AH. Depression and anxiety associated with cardiovascular disease among persons aged 45 years and older in 38 states of the United States, 2006. Prev Med 2008;46: 445-50.

15. Davis J, Fujimoto RY, Juarez DT, Hodges KA, Asam JK. Major depression associated with rates of cardiovascular disease state transitions. Am J Manag Care 2008;14:125-8.

16. Chilcot J, Wellsted D, Da Silva-Gane M, Farrington K. Depression on dialysis. Nephron 2008;108:c25664.

17. Lustman PJ, Clouse RE. Treatment of depression in diabetes: impact on mood and medical outcome. J Psychosom Res 2002;53:917-24.

18. Sharpe L, Sensky T, Timberlake N, Ryan B, Brewin CR, Allard S. A blind, randomized, controlled trial of cognitive-behavioural intervention for patients with recent onset rheumatoid arthritis: preventing psychological and physical morbidity. Pain 2001;89:275-83.

19. Sambamoorthi U, Walkup J, Olfson M, Crystal S. Antidepressant treatment and health services utilization among $\mathrm{HIV}$-infected medicaid patients diagnosed with depression. J Gen Intern Med 2000;15: 311-20.

20. Roose SP, Glassman AH, Seidman SN. Relationship between depression and other medical illnesses. JAMA 2001;286:1687-90.

21. Nejtek VA, Brown ES, Khan DA, Moore JJ, Van Wagner J, Perantie DC. Prevalence of mood disorders and relationship to asthma severity in patients at an inner-city asthma clinic. Ann Allergy Asthma Immunol 2001;87:129-33.

22. Consoli SM. [Depression and associated organic pathologies, a still under-estimated comorbidity. Results of the DIALOGUE study]. Presse Med 2003; 32:10-21.

23. Koike AK, Unutzer J, Wells KB. Improving the care for depression in patients with comorbid medical illness. Am J Psychiatry 2002;159:1738-45.

24. Steffens DC, McQuoid DR, Krishnan KRR. The 
Duke Somatic Treatment Algorithm for Geriatric Depression (STAGED) approach. Psychopharmacol Bull 2002;36:58-68.

25. Krishnan KRR. Comorbidity and depression treatment. Biol Psychiatry 2003;53:701-6.

26. Brown C, Schulberg HC, Prigerson HG. Factors associated with symptomatic improvement and recovery from major depression in primary care patients. Gen Hosp Psychiatry 2000;22:242-50.

27. Saavedra JE, Mezzich JE, Salloum IM, Kirisci L. Predictive validity of the physical disorders axis of the DSM multiaxial diagnostic system. J Nerv Ment Dis 2001;189:435-41.

28. Sambamoorthi U, Olfson M, Wei W, Crystal S. Diabetes and depression care among medicaid beneficiaries. J Health Care Poor Underserved 2006;17: 141-61.

29. Regier DA, Narrow WE, Rae DS, Manderscheid RW, Locke BZ, Goodwin FK. The de facto US mental and addictive disorders service system. Epidemiologic catchment area prospective 1-year prevalence rates of disorders and services. Arch Gen Psychiatry 1993;50:85-94.

30. Wang PS, Lane M, Olfson M, Pincus HA, Wells KB, Kessler RC. Twelve-month use of mental health services in the United States: results from the $\mathrm{Na}$ tional Comorbidity Survey Replication. Arch Gen Psychiatry 2005;62:629-40.

31. Kessler RC, Demler O, Frank RG, et al. Prevalence and treatment of mental disorders, 1990 to 2003. N Engl J Med 2005;352:2515-23.

32. Roundy K, Cully JA, Stanley MA, et al. Are anxiety and depression addressed in primary care patients with chronic obstructive pulmonary disease? A chart review. Prim Care Companion J Clin Psychiatry 2005;7:213-8.

33. Williams JW Jr, Noel PH, Cordes JA, Ramirez G, Pignone $M$. Is this patient clinically depressed? JAMA 2002;287:1160-70.

34. Tylee A, Walters P. Early recognition and management of depression in primary care. In: Early Detection and Management of Mental Disorders. Maj M, Lopez-Ibor JJ, Sartorius N, Sato M, Okasha A (eds.). Chichester: John Wiley; 2005.

35. Aragones E, Labad A, Pinol JL, Lucena C, Alonso Y. Somatized depression in primary care attenders. J Psychosom Res 2005;58:145-51.

36. US Department of Health and Human Services, US Public Health Service, Office of the Surgeon General. Mental health: culture, race, and ethnicity: a supplement to mental health: a report of the Surgeon General. Washington, DC: US Department of Health and Human Services; 2001.

37. Jaen CR, Stange KC, Nutting PA. Competing demands of primary care: a model for the delivery of clinical preventive services. J Fam Pract 1994;38: $166-71$.

38. Stange KC, Jaen CR, Flocke SA, Miller WL,
Crabtree BF, Zyzanski SJ. The value of a family physician. J Fam Pract 1998;46:363-8.

39. Higashi T, Wenger NS, Adams JL, et al. Relationship between number of medical conditions and quality of care. N Engl J Med 2007;356:2496-504.

40. Min LC, Wenger NS, Fung C, et al. Multimorbidity is associated with better quality of care among vulnerable elders. Medical Care 2007;45:480-8.

41. Turner BJ, Hollenbeak CS, Weiner M, Ten Have T, Tang SSK. Effect of unrelated comorbid conditions on hypertension management. Ann Intern Med 2008;148:578-86.

42. Kahn LS, Fox CH, Olawaiye A, Servoss TJ, McLean-Plunkett E. Facilitating quality improvement in physician management of comorbid chronic disease in an urban minority practice. J Natl Med Assoc 2007;99:377-83.

43. Vogeli C, Shields AE, Lee TA, et al. Multiple chronic conditions: prevalence, health consequences, and implications for quality, care management, and costs. J Gen Intern Med 2007;22(Suppl 3):391-5.

44. Klinkman MS. Competing demands in psychosocial care. A model for the identification and treatment of depressive disorders in primary care. Gen Hosp Psychiatry 1997;19:98-111.

45. Williams JW Jr. Competing demands: does care for depression fit in primary care? J Gen Intern Med 1998;13:137-9.

46. Rost K, Nutting P, Smith J, Coyne JC, CooperPatrick L, Rubenstein L. The role of competing demands in the treatment provided primary care patients with major depression. Arch Fam Med 2000; 9:150-4.

47. Goldberg RW, Kreyenbuhl JA, Medoff DR, et al. Quality of diabetes care among adults with serious mental illness. Psychiatr Serv 2007;58:536-43.

48. Borowsky SJ, Rubenstein LV, Meredith LS, Camp $\mathrm{P}$, Jackson-Triche M, Wells KB. Who is at risk of nondetection of mental health problems in primary care? J Gen Intern Med 2000;15:381-8.

49. Koike AK, Unutzer J, Wells KB. Improving the care for depression in patients with comorbid medical illness. Am J Psychiatry 2002;159:1738-45.

50. Kurdyak PA, Gnam WH. Medication management of depression: the impact of comorbid chronic medical conditions. J Psychosom Res 2004;57:565-71.

51. Harman JS, Edlund MJ, Fortney JC, Kallas H. The Influence of comorbid chronic medical conditions on the adequacy of depression care for older Americans. J Am Geriatr Soc 2005;53:2178-83.

52. Kroenke K, Spitzer RL, Williams JB. The Patient Health Questionnaire-2: validity of a two-item depression screener. Med Care 2003;41:1284-92.

53. Spitzer RL, Kroenke K, Williams JB. Validation and utility of a self-report version of PRIME-MD: the PHQ primary care study. Primary Care Evaluation of Mental Disorders Patient Health Questionnaire. JAMA 1999;282:1737-44. 
54. Kroenke K, Spitzer RL, Williams JB. The PHQ-9: validity of a brief depression severity measure. J Gen Intern Med 2001;16:606-13.

55. Rost K, Smith J. Retooling multiple levels to improve primary care depression treatment. J Gen Intern Med 2001;16:644-5.

56. Kroenke K, Spitzer RL. A new depression and diagnosis severity measure. Psychiatry Ann 2002;32:50921.

57. The MacArthur Foundation. The Macarthur Initiative on Depression, Primary Care. Depression Management Toolkit, version 1.3. 2003-2006. Available at http://www.depression-primarycare.org/clinicians/ toolkits/. Accessed 21 October 2008.

58. Charlson ME, Pompei P, Ales KL, MacKenzie CR. A new method of classifying prognostic comorbidity in longitudinal studies: development and validation. J Chronic Dis 1987;40:373-83.

59. Charlson M, Szatrowski TP, Peterson J, Gold J. Validation of a combined comorbidity index. J Clin Epidemiol 1994;47:1245-51.

60. Fischer LR, Wei F, Solberg LI, Rush WA, Heinrich RL. Treatment of elderly and other adult patients for depression in primary care. J Am Geriatr Soc 2003;51:1554-62.

61. Bertakis KD, Helms LJ, Callahan EJ, Azari R, Leigh $\mathrm{P}$, Robbins JA. Patient gender differences in the diagnosis of depression in primary care. $\mathrm{J}$ Womens Health Gend Based Med 2001;10:689-98.

62. Simpson SM, Krishnan LL, Kunik ME, Ruiz P. Racial disparities in diagnosis and treatment of depression: a literature review. Psychiatr Q 2007;78:314.

63. Himelhoch S, Weller WE, Wu AW, Anderson GF, Cooper LA. Chronic medical illness, depression, and use of acute medical services among Medicare beneficiaries. Med Care 2004;42:512-21.

64. Henk HJ, Katzelnick DJ, Kobak KA, Greist JH, Jefferson JW. Medical costs attributed to depression among patients with a history of high medical expenses in a health maintenance organization. Arch Gen Psychiatry 1996;53:899-904.

65. Coyne JC, Schwenk TL, Fechner-Bates S. Nondetection of depression by primary care physicians reconsidered. Gen Hosp Psychiatry 1995;17:3-12.

66. Schulberg HC, Katon W, Simon GE, Rush AJ. Treating major depression in primary care practice: an update of the Agency for Health Care Policy and Research Practice Guidelines. Arch Gen Psychaitry 1998;55:1121-7.

67. US Department of Health and Human Services, Public Health Service Agency for Health Care Policy and Research. Clinical Practice Guideline, Depression in Primary Care, vol. 2. Treatment of Major Depression, 1993. Washington, DC: US Department of Health and Human Services.

68. Charbonneau A, Rosen AK, Ash AS, et al. Measuring the quality of depression care in a large integrated health system. Med Care 2003;41:669-80.

69. Kerr EA, McGlynn EA, Van Vorst KA, Wickstrom SL. Measuring antidepressant prescribing practice in a health care system using administrative data: implications for quality measurement and improvement. Jt Comm J Qual Improv 2000;26:203-16.

70. de Jonghe F, Kool S, van Aalst G, Dekker J, Peen J. Combining psychotherapy and antidepressants in the treatment of depression. J Affect Disord 2001; 64:217-29.

71. Casacalenda N, Perry JC, Looper K. Remission in major depressive disorder: a comparison of pharmacotherapy, psychotherapy, and control conditions. Am J Psychiatry 2002;159:1354-60.

72. Hepner KA, Rowe M, Rost K, et al. The effect of adherence to practice guidelines on depression outcomes. Ann Intern Med 2007;147:320-9.

73. Meredith LS, Rubenstein LV, Rost K, et al. Treating depression in staff-model versus network-model managed care organizations. J Gen Intern Med 1999; 14:39-48.

74. Ward E, King M, Lloyd M, et al. Randomised controlled trial of non-directive counselling, cognitivebehaviour therapy, and usual general practitioner care for patients with depression. I: Clinical effectiveness. BMJ 2000;321:1383-8.

75. Bedi N, Chilvers C, Churchill R, et al. Assessing effectiveness of treatment of depression in primary care. Partially randomised preference trial. Br J Psychiatry 2000;177:312-8.

76. Aursnes I, Tvete IF, Gaasemyr J, Natvig B. Suicide attempts in clinical trials with paroxetine randomised against placebo. BMC Med 2005;3:14.

77. Susman JL, Crabtree BF, Essink G. Depression in rural family practice. Easy to recognize, difficult to diagnose. Arch Fam Med 1995;4:427-31. 